\title{
Dagens Rødhette i en flerkulturell kontekst - mulighet for en ny identitet?
}

\begin{abstract}
The starting point for this article is the tendency in recent Norwegian children's and Ya fiction to thematize cultural encounters in an increasingly multicultural and globalized world. The picturebook Little Miss Eye Flap (Skylappjenta, 2009) written by the Pakistani-Norwegian author and actor Iram Haq and illustrated by Endre Skandfer, presents a modern version of traditional folktales such as Little Red Riding Hood and Rapunzel. However, in the traditional structure of home - away home this story places particular emphasis on the phase of homelessness, not providing any safe return to harmony. This condition of liminal space between cultures is discussed in light of the concepts of reflexive identity (Anthony Giddens), cultural identity (Stuart Hall) and hybridity (Homi K. Bhabha). Written by an author who herself comes from a multicultural background, and who presents the book as partly autobiographical, Little Miss Eye Flap offers a double perspective on questions of cultural identity, including critical views on Norwegian as well as Pakistani tradition. The book ends by showing Miss Eye Flaps in a big open space, where it is more certain what she leaves behind than what the future will bring. The open ending and the focalization of the girl with the multicultural background opens up to a discursive space where new hybrid identities may be explored.
\end{abstract}

Keywords: picturebooks, cultural identity, hybridity, folktale, intertextuality, Little Red Riding Hood

Nøkkelord: bildebøker, kulturell identitet, hybriditet, eventyr, intertekstualitet, Rødhette

Norsk barne- og ungdomslitteratur har lenge dreid seg om norske miljøer og vist påfallende lite interesse for de multikulturelle møtene som økt mobilitet har ført med seg (Kiil). Det siste tiåret har denne tendensen snudd, og barnelitteraturen har kommet med sitt bidrag til forståelsen av en ny type kulturmøter som er typiske for en senmoderne, globalisert kultur. I sin studie om globalisering i norsk barnelitteratur (Naveen) omtaler Neha Naveen 13 bøker 
med slike tema fra perioden 2000-2010. En av bøkene er bildeboka Skylappjenta (2009) av Iram Haq og Endre Skandfer, som ble publisert parallelt med animasjonsfilmen med samme tittel. Haq og Skandfer har tidligere arbeidet mest med film. Iram Haq, som har pakistansk-norsk bakgrunn, har skrevet manus og regissert, Skandfer står for illustrasjoner og animasjon. Målgruppa for bildeboka er i følge forlaget 10-15 år. Filmen appellerer antageligvis også til eldre ungdom.

Skylappjenta handler om kulturmøtet mellom den beskyttede, nærmest innestengte innvandrerjenta og norsk ungdomskultur. Slike kulturmøter står sentralt i artikkelen "Home, Homelessness and Liminal Spaces" av Mavis Reimer og Clare Bradford. De presenterer en lesemåte aktualisert av bøker om kulturmøter ved kolonialiseringen av Canada og Australia, men konkluderer med at den også kan være relevant for andre bøker som tematiserer tverrkulturelle og interkulturelle forhold (Reimer og Bradford, 215). Reimer og Bradford tar utgangspunkt i en etablert sjangerstruktur i barnelitteraturen som beveger seg fra en harmonisk og trygg, om enn begrenset og kjedelig, utgangsposisjon, via hjemløshet tilbake til en ny hjemmesituasjon. De hevder at når barnelitteraturen har vært særlig opptatt av å hente både protagonister og lesere hjem igjen til en trygg og harmonisk slutt, kan det være uttrykk for en lesemåte rotfestet i vestlig kultur og ideologi, og de etterlyser mer analytisk oppmerksomhet omkring den hjemløse fasen. Her finner de potensialet for "unhoused, decentered and exilic energies", med et sitat fra Edward Said (Culture and Imperialism 332). Said er mest kjent for sitt begrep "orientalisme" som han utviklet for å betegne hvordan vestlige kritikere oppfatter og representerer østlig kultur (Orientalismen).

At slike narrative strukturer er i endring, særlig i ungdomslitteraturen, påpeker også Åsfrid Svensen i sin artikkel fra 1996 om nye narrative strukturer i moderne barne- og ungdomslitteratur "Fra store fortellinger til små historier". Hun knytter strukturen hjemme - borte - hjemme til "en stor fortelling i vår kultur: en fortelling om et barns medfødte, stabile identitet og et livsløp som springer ut av barnets naturgitte forutsetninger" (Svensen, 284). Dette blir problematisert i 1980- og 90-årenes barne- og ungdomslitteratur, hevder Svensen: "Det kaotiske midtstadiet i dannelsesromanen ser ut til å ha erobret hele fortellingen, og uten at det skjer noen avklarende harmonisering til slutt." (ibid.). Disse forskerne ser altså slike endringer i narrative strukturer som uttrykk for identitetsarbeid, enten det er knyttet til en turbulent ungdomstid eller til nye kulturmøter i en globalisert verden. 
Hjemme - borte - hjemme strukturen er særlig tydelig etablert i vestlig eventyrtradisjon. Skylappjenta spiller helt klart på eventyrtradisjonen, blant annet eventyret om Rødhette. Protagonisten har aldri vært utenfor husets fire vegger før hun en dag må gå til sin syke bestemor med mat. På veien møter hun en norsk gutt som hun forelsker seg i og en onkel som i samarbeid med bestemoren prøver å sende henne til Langtvekkistan for å gifte henne bort der. Landet Pakistan nevnes ikke eksplisitt i teksten, men onkelen heter Chacha som betyr onkel på urdu. Dessuten snakker de urdu i filmen.

Skylappjenta må forholde seg til kulturer med til dels motstridende verdier. Ute blant jevnaldrende opplever hun en moderne vestlig kultur preget av konsum, seksualitet og overfladiskhet mens hennes hjemlige omgivelser kjennetegnes av tradisjonelle pakistanske verdier basert på eldgamle æresbegreper. Hvilke forventninger og utfordringer blir hun eksponert for og hvordan influerer krysspresset mellom disse to kulturene på hennes identitetsutvikling som ung kvinne?

\section{Eventyrtradisjonen}

Allerede på første oppslag viser Skylappjenta sin tilknytning til eventyrtradisjonen ved åpningsordene: "Det var en gang". Den

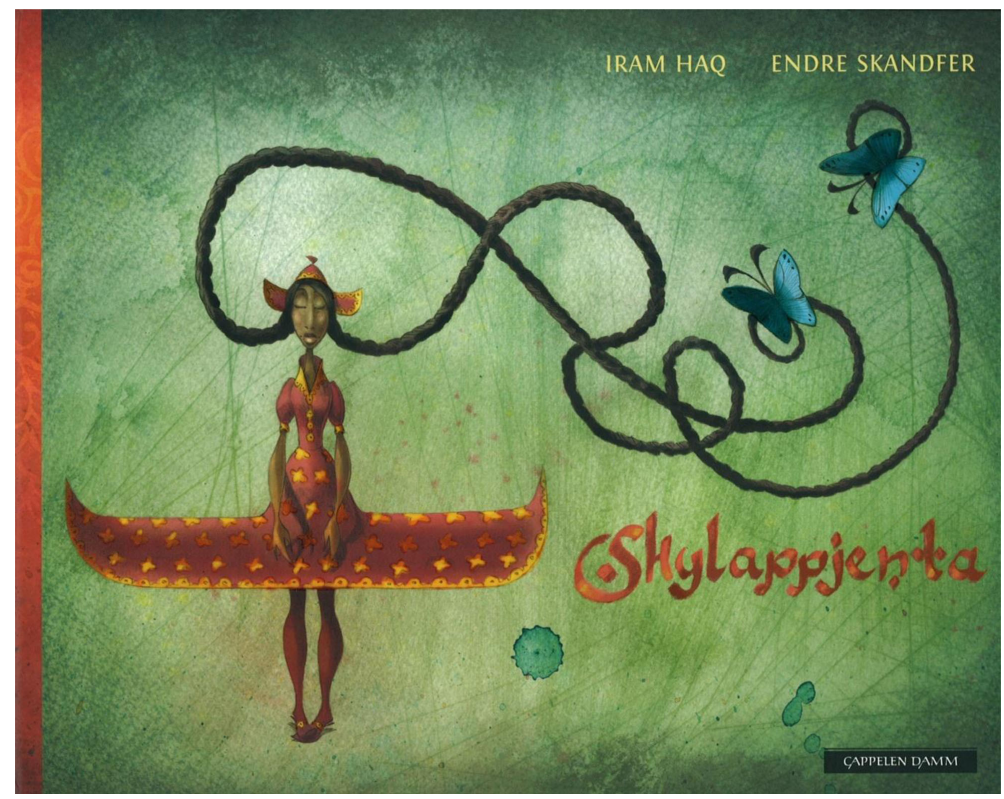

Figur I. Omslaget til Skylappjenta understreker slektskapet med eventyret om Rapunsel. Gjengitt med tillatelse fra Endre Skandfer og forlaget. 
første opplagte referansen til Rødhette kommer i oppslag 2, der moren trer en rød hette med skylapper ned over hodet til jenta "så hun bare kunne se og høre det som var rett foran henne". Men i første oppslag finner vi også klare paralleller til eventyret om Rapunsel. Utseendemessig blir likheten dem imellom understreket ved at bildene viser Skylappjenta med svært lange fletter gjennom hele boka, bortsett fra de to siste oppslagene der flettene har løsnet og håret henger løst. Bildene på det første oppslaget viser også Skylappjenta høyt oppe i et vindu, og på taket av huset. Slik ser vi at både protagonisten i dette eventyret og jenta i Skylappjenta isoleres fra verden utenfor. Som Åse Marie Ommundsen også påpeker, strekker de lange flettene hennes seg ut i verden, og indikerer dermed en lengsel etter et annet og friere liv (233).

Rapunsel tilhører en gruppe eventyr som ofte blir tolket som fortellinger om pubertet og seksuell oppvåkning som ung kvinne (Bettelheim, 361; May, 158). Andre eksempler fra den norske tradisjonen er Kvitebjørn Kong Valemon, Østenfor sol og vestenfor måne og Kari Trestakk. Disse skal vi komme tilbake til etter at vi har sett nærmere på den mest opplagte eventyrreferansen: Rødhette. Dette eventyret har en lang og produktiv historie som intertekstuell referanse, som Sandra L. Beckett understreker i Red Riding Hood for All Ages - A Fairy-Tale Icon in Cross-Cultural Contexts: "Little Red Riding Hood's well-known tale is undoubtedly the most effective of all literary intertexts" (3). I ulike versjoner har denne historien henvendt seg til lesere i ulike aldersgrupper og livssituasjoner.

Den eldste skriftlige versjonen vi kjenner, er Charles Perraults nedtegning fra 1697. I hans versjon Le Petit Chaperon Rouge er den doble adressaten tydelig (Wall), ikke minst $\mathrm{i}$ avslutningen som kan leses som en advarsel til unge kvinner om å passe seg for de farligste ulvene, nemlig de som går på to ben og har gode manerer (Skjønsberg). I Brødrene Grimms versjon Rotkäppchen fra 1812 er de seksuelle undertonene borte. Istedenfor vektlegges morens formaninger om å passe seg for skogens mulige farer, og hvordan Rødhette lærer å innrette seg etter disse normene. I den nye slutten som legges til, samarbeider Rødhette og bestemor om å overliste ulven neste gang det dukker opp et slikt udyr. I denne versjonen er den lykkelige slutten med på å understreke den enkle adressaten til barnet. Her etableres det kjente eventyrmønsteret hjemme - borte hjemme. Rødhette går ut i skogen, glemmer morens formaninger, lærer av sine feil, og vender hjem igjen til folden. Denne symmetriske strukturen passer helt med et statisk tradisjonssamfunn der skikker videreføres gjennom generasjoner. 
Både i Rødhette, Rapunsel og andre beslektede eventyr dreier altså konflikten seg om de farer som lurer når ei ung jente begir seg ut i verden på egen hånd. Protagonisten i disse eventyrene er det Vladimir Propp karakteriserer som en offerhelt ("victimized heroes"), som står i klar motsetning til den andre heltetypen Propp finner i russiske undereventyr: eventyreren ("seekers") (36). Mens eventyrerhelten begir seg ut i verden for å erobre den, frivillig og full av eventyrlyst, blir offerhelten bortført eller drevet ut av mangel eller nød. Rødhette må gå alene gjennom skogen fordi bestemor er syk, Rapunsel havner i tårnet dypt inne i skogen fordi faren stjal Rapunselsalat til moren da hun trengte medisin under svangerskapet, og protagonistene i eventyr med skjønnheten og udyret-motiv havner hos udyret fordi familiene deres er fattige eller har gitt etter for et stort begjær. Det er neppe tilfeldig at så mange av disse offerheltene er kvinner.

Det er likevel en viss forskjell på fortellingen om lille Rødhette og noen av de andre fortellingene vi har brukt som eksempler her. Mens Rødhette, i alle fall i Grimm-versjonen, vender tilbake til tryggheten hos mor, ender de andre heltinnene med å nedkjempe motstanden og skape seg en ny tilværelse. Det gjelder til en viss grad Rapunsel som gjenforenes med sin prins etter store offer fra dem begge. Men særlig er det påfallende at protagonistene i de tre norske eventyrene (Østenfor sol og vestenfor måne, Kvitebjørn kong Valemon og Kari Trestakk) selv må søke aktivt ut i verden for å redde sin prins fra trolldommen. Her får vi en todelt fortellerstruktur der protagonisten gjennomgår en vending fra offerhelt til eventyrer. Overgangen kan tolkes som pubertetens overgang fra barn til voksen, slik Hilde Kramers illustrasjoner understreker i bildebokversjonen av Østenfor sol og vestenfor måne, der jenta gjennomgår en tydelig kroppslig forandring fra første til andre fase. I andre del av disse eventyrene framstår jentene som selvstendige individer som aktivt oppsøker udyret/prinsen og overvinner motstand og fare for å redde ham ut av trollkvinnens klør og opprette en selvstendig kjærlighetsrelasjon. I disse eventyrene er strukturen annerledes enn i de klassiske europeiske vi finner hos Brødrene Grimm: Hjemme skjøvet ut - oppvåkning - ut i verden - kamp og seier - etablering av ny harmoni.

\section{Krysspress mellom to kulturer}

Et trekk som Skylappjenta har felles med de kvinnelige protagonistene $\mathrm{i}$ eventyrene, er at hun stenges inne for å skjermes fra verdens farer og fristelser. Allerede i utgangspunktet har hun litt av 
eventyreren i seg, hun drømmer om verden utenfor som hun bare får små glimt av gjennom tv-skjermen. Da Skylappjenta en dag klatrer opp på taket for å ordne TV-antennen, fortaper hun seg i de forlokkende fremmede lydene. Men konflikten blir tydelig ved at hun raskt blir irettesatt av moren med ordene "Slik nysgjerrighet kan ødelegge selv den reneste sjel for resten av livet!" (oppslag 2). Dette er foranledningen til at moren drar den røde lua med øreklaffene ned over ørene hennes. Skylapplua fungerer som et konkret middel til å håndheve den patriarkalske loven for kvinner om å følge den rette og smale vei ved å være lydig og passiv.

Da Skylappjenta en dag får beskjed om å gå til den syke bestemoren med mat, advarer moren henne mot å snakke med fremmede. Denne formaningsscenen i Rødhette-eventyret setter ofte leseren på sporet av hva som anses som farlig. I den siste advarselen presiseres det at det er gutter hun skal passe seg for, og den potensielle straffen for å avvike fra normen er at hun aldri vil bli gift. Bildene på de neste oppslagene viser kontrasten mellom det vakre blomsterlandskapet jenta ser mellom skylappene, og den aktiviteten som moren ikke vil at datteren skal eksponeres for, som kan skimtes i oppslagenes mørkere partier. Leseren kan se hvordan jentas jevnaldrende flørter og bryter islams påbud ved å drikke alkohol og grille en gris. Konflikten vises i samspillet mellom verbalteksten, som formidler jentas perspektiv, og bildene som også inkluderer morens advarsler og onkel Chachas overvåking.

\section{Norsk blikk?}

På vei til bestemoren møter Skylappjenta Normann, en maskulin stereotypi med røtter i norske folkeeventyr. Normann har flere trekk til felles med Askeladden, den mest kjente eventyrfiguren i Norge.

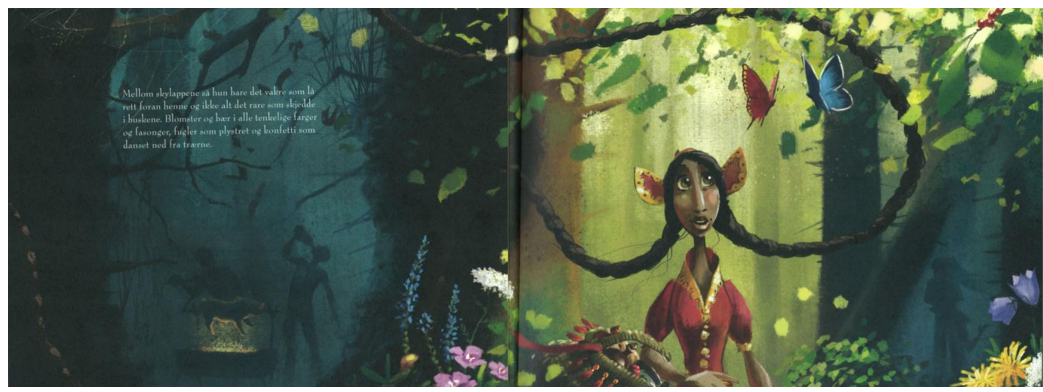

Figur 2. Oppslag 3 viser visuelt skillet mellom jentas begrensete perspektiv og leserens perspektiv, som også inkluderer det som foregår i de mørke skyggene. Gjengitt med tillatelse fra Endre Skandfer og forlaget. 
Denne figuren kan også finnes i andre lands folklore (Witoszek, Norske naturmytologier 86), men i Norge framstår Askeladden som den prototypiske eventyrhelten. Både Normann og Askeladden er sterkt bestemt på å oppnå sine mål. Når Askeladden i eventyret Prinsessen som ingen kunne målbinde finner gjenstander som kan hjelpe han til å nå målet, roper han ut: "Jeg fant, jeg fant!" De samme ordene roper Normann når han endelig har klart å overtale Skylappjenta til å slå følge med ham, samtidig som han gjør et urnorsk hallingkast. Her ligger muligheten for at hun objektiveres til noe som han kan bruke for å nå sine mål. Men Normann har også mer omsorgsfulle og sjarmerende sider. Som når Askeladden møter trengende i eventyret, deler han nistematen sin med henne. Problemet i denne sammenhengen er at han også skjenker henne alkohol. Slik trekkes trusselen fra skyggene inn i Skylappjentas egen verden. Og Normanns nærgåenhet fører til et vendepunkt der Skylappjenta kommer til seg selv og husker på ærendet sitt.

Framstillingen av Normann skjer i et dobbelt perspektiv. På den ene siden er han den glade gutten som gjerne vil dele godene med jenta han møter i skogen. Samtidig er han nysgjerrig, overfladisk og selvsentrert inntil det banale, for eksempel når han gir henne kompliment for hudfargen hennes: "Den brunfargen din er jammen lekker. Har du solt deg mye?" (oppslag 8). Og han har usvikelig tro på at hun skal falle for ham. Selv etter at han har skremt henne med sine tilnærmelser, roper han etter henne: "vi har jo et eventyr sammen!" (ibid.). Slik gjenspeiler han Askeladdens freidighet og selvtillit mot alle odds.

Forskjellen kommer fram ved at Normann ikke er plassert lavest på rangstigen slik som Askeladden er i folkeeventyrene. Dermed får hans erobring ikke den samme karakteren av positiv oppdrift, den kan snarere virke som en bortskjemt gutts selvopptatthet. Normann deler riktignok nista si med Skylappjenta, men er ute av stand til å se hva han utsetter henne for ved å ta alkohol og svinekjøtt for uproblematiske goder. Normanns mest positive heltekvaliteter viser seg ved at han oppsøker henne i bestemors hus og redder henne fra onkel Chachas og bestemors planer om å sende henne til Langtvekkistan (oppslag 11). Men to oppslag senere merker han ikke en gang at hun faller av når hun står bakpå skiene hans og prøver å holde seg fast.

Uttrykt i Rødhette-termer kan vi si at Normann-skikkelsen har litt av både ulven og jegeren i seg. Dermed blir både konflikt og løsning i Skylappjenta som senmoderne eventyr grunnleggende ambivalente. Framstillingen av Normann kan også leses som en 
ironisk kommentar til dagens norske selvforståelse. Som et speilbilde av Askeladden-figuren liker nordmenn å se seg selv som det lille landet som har funnet nøkkelen til det gode liv. Den polsknorske kulturhistorikeren Nina Witoszek har karakterisert denne selvoppfatningen som et "regime of goodness". Det er preget av myter om at norsk identitet er grunnlagt på natur, fred og kristen etos, og videreført i moderne versjon i den sosialdemokratiske modellen (Witoszek, The Origins of the "Regime of Goodness"). Men som den moderne varianten vi møter i Normanns skikkelse, kan nordmenn samtidig framstå som bortskjemte og ubetenksomme med sin oljerikdom og sitt høye forbruk.

Mens Askeladden er fokalisert i eventyrene om ham, er det jenta og ikke Normann som er fokalisert i Skylappjenta. Leseren kommer dermed ikke like tett inn på Normann, og møter hans oppfatning av verden først og fremst gjennom replikkene, der han avslører et tydelig orientalistisk blikk (Said, Orientalismen) når han omtaler Skylappjenta som "eksotisk" ved første møte. Også hans handlinger definerer det norske som det selvfølgelige utgangspunktet for relasjonen mellom de to, enten det gjelder måten han flørter og fester på, eller at han tar henne med på ski uten hensyn til hennes bakgrunn og ferdigheter. Han ser alt fra sitt ståsted og definerer henne som den som er annerledes, og dermed forventes å innrette seg etter hans skikker.

\section{Pakistansk blikk?}

Noe av det som særpreger en bok som Skylappjenta er at den er skrevet med fotfeste i både norsk og pakistansk kultur. Iram Haq presenterer den selv som en bok som tar i bruk hennes egne erfaringer som annen generasjons innvandrer i Norge. Fra en slik posisjon er det mulig å nærme seg begge kulturer med et blikk som ser kulturen både innenfra og utenfra. Teksten utfordrer leseren ved at Skylappjentas perspektiv inkluderer både forståelsen for den pakistanske tenkemåten og en kritisk holdning til konsekvensene for enkeltindividet.

Mens både verbaltekst og bilde formidler Normann og Skylappjenta i løssluppen dans, vises det bare i bildene at onkelen sitter voktende i en svart drosje på høyre side av oppslag 4. En slik svart bil er i følge Sandra L. Beckett (Red Riding Hood for All Ages, 51) ganske vanlig som attributt til ulven i flere av de moderne gjenfortellingene av eventyret om Rødhette. I Skylappjenta er det ingen direkte seksuelle undertoner knyttet til onkelen, men indirekte er hans voktende blikk en påminnelse om jentas framtidige 
seksualitet. Hans funksjon er å være familiens overhode. Denne makten kommer tydelig fram i verbalteksten: "en sterk vind løftet alle blomstene opp med røttene og blåste dem langt vekk. Vinden kom fra den mørke stemmen til onkel Chacha" (oppslag 4). Også i bildene tydeliggjøres det at hans styrke og innflytelse ikke står tilbake for naturkreftene.

I likhet med ulven drar onkelen til bestemors hus, legger seg i hennes seng og venter på Skylappjenta der. Men han skal verken forføre eller fortære henne. Hans plan er å ufarliggjøre henne ved å tvangssende henne på en "oppdragelsestur". Verbalteksten forteller hvor gledeløst målet for denne turen er: "De ville sende henne til Langtvekkistan, hvor ingen ler eller danser discodans." Hennes individuelle livsutfoldelse må ofres for at ikke familien som kollektiv skal vanæres. I følge den kulturen onkelen vokter, er Skylappjenta forpliktet til å respektere både ham og de verdiene han representerer. Dette kravet om respekt blir understreket av at ordet står skrevet på drosjedøra. Selve ordet respekt ses bare i bildene, men det er et nøkkelord for å forstå bakgrunnen for familiens handlinger.

Også bestemorens oppførsel kan leses inn i den samme æresrelaterte konteksten. Hun framstår som tradisjonens sterke vokter når hun med en sterkt forlenget pekefinger sier: "Du tilhører oss!" (oppslag 13). I bildet ser vi at situasjonen har tatt fra jenta både styrke og størrelse. Det er jentas skygge som viser at hun ønsker å unnslippe.

Samtidig understreker verbalteksten at det er Normann som gir henne styrken til å gjennomføre oppbruddet. Å bryte med familien

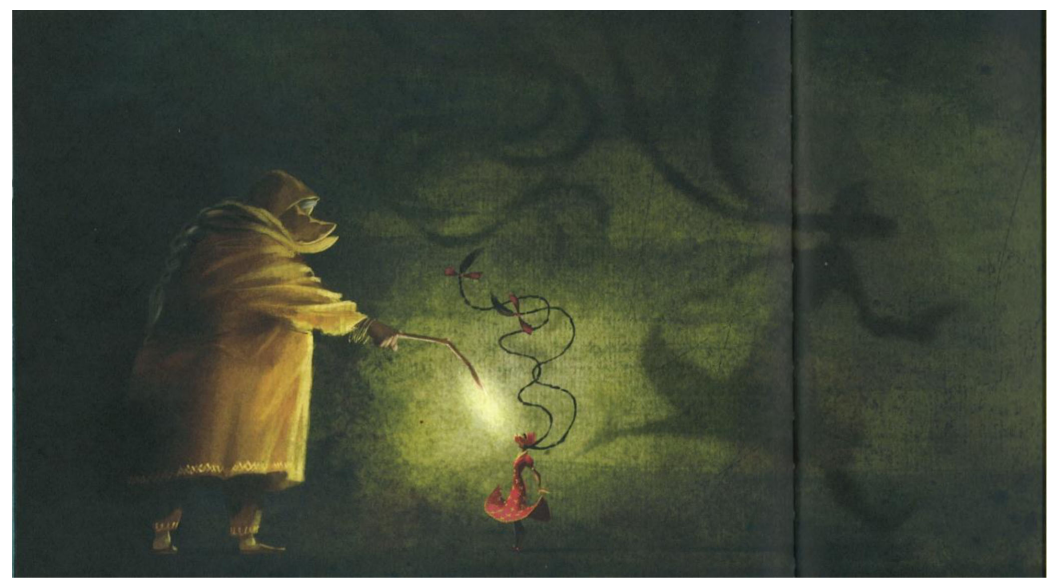

Figur 3. Avbildningen av bestemor og Skylappjenta understreker maktforholdet mellom dem, samtidig som skyggene viser hva jenta ønsker. Oppslag I3. Gjengitt med tillatelse fra Endre Skandfer og forlaget. 
er et ugjenkallelig valg, og det er bestemoren som fastslår det: "Om du forlater oss nå, vil alle broer være brent! For godt!" (oppslag 14).

I Honor (1994) sammenligner historikeren Frank Henderson Stewart ideer fra Europas middelalder med ikke-vestlige samfunn for å forstå æresbegrepet. Han argumenterer med at ære må sees på som en rettighet, først og fremst en rettighet til å bli respektert. Den norske sosialantropologen Unni Wikan understreker at et slikt æresbegrep har vist seg nyttig som et redskap til å beskrive og forstå en del ikke-vestlige samfunn. Med de nye folkevandringene og etableringen av et flerkulturelt Norden er begrepet ikke bare nyttig, men påkrevd for å forstå den pågående utviklingen i skandinaviske velferdssamfunn.

Ære handler om en rett til respekt, i betydningen krav på respekt. Samfunnet har plikt til å yte personen respekt, gitt at reglene for æreskodeksen er overholdt. I motsatt fall mister personen ære. [...] Vanære kan skje ikke bare ved personens egne handlinger, men også på to andre måter: mennesker som står personen nær (familien eller slekten) kan vanæres og dermed ramme ham; eller en kvinne han har myndighet over - en datter, søster, kone, kusine eller niese, kan kaste skam over ham ved sine handlinger. Det siste gjelder spesielt i forhold til seksualitet. På denne måten blir kvinners kyskhet et familieanliggende (For crens skyld, 72-73).

Wikan understreker da også at dette æresbegrepet ikke er en individuell sak, men et kollektivt anliggende hvor makt og kontroll er viktige styringsmekanismer. Ut fra en slik forståelse kommer ikke bestemorens avvisning som en overraskelse når Skylappjenta bryter de uskrevne lovene ved å rømme. Den eneste måten å gjenopprette æren på, er å ekskludere henne. Wikan påpeker da også at eksil kan være en løsning på slike æresrelaterte problemer. Det pakistanske blikket på æresbegrepet viser at det hviler et tungt ansvar på onkel Chacha for å passe på at familiens status og posisjon opprettholdes. Et feiltrinn fra Skylappjentas side får store konsekvenser for hele familien.

\section{Identitet og kultur}

Sandra L. Beckett undersøker flere gjenfortellinger av eventyret i Recycling Red Riding Hood. I mange av de moderne variantene forandres det konvensjonelle gender-repertoaret kjent fra tradisjonelle patriarkalske kulturer. Gjenfortellingene er ofte en parodi hvor maktforholdene snus på hodet og Rødhette presenteres i et 
maskulint gender-repertoar. $\AA$ se på hjemmet som begrensende tilhører vanligvis den mannlige diskursen. Hvis en kvinnelig protagonist forlater hjemmet, følger hun som oftest strukturen hjemme - borte - hjemme. Skylappjenta bryter dette mønsteret uten at hun dermed framstår som maskulin. Som innvandrerjente står Skylappjenta i en tilsynelatende maktesløs posisjon når hun velger å trosse familiens påbud og advarsler. Hennes hjemløshet er av et helt annet omfang enn den som skildres i den tradisjonelle ungdomsboka hvor protagonisten tar et oppgjør med hjemmet. For Skylappjenta må ikke bare forlate det konkrete hjemmet, men hun blir også utestengt fra fellesskap, tilhørighet og tradisjoner. I motsetning til sine søstre i eventyrene har hun ingen gode hjelpere eller magiske gjenstander å hjelpe seg med. I bildeboka kommer denne totale løsrivelsen fram ved at hun i de to siste oppslagene framstilles mot en hvit bakgrunn. Mens de andre oppslagene er mettet med farger og detaljerte framstillinger av jentas omgivelser, ender historien med å plassere henne i et stort tomt rom, der bare vage konturer av byen $\mathrm{i}$ aller siste oppslag viser hvor hun er på vei.

Den situasjonen som Skylappjenta befinner seg i ved bokas avslutning, kan sammenlignes med det Reimer og Bradford karakteriserer som "liminal space". Resepsjonsforskeren Anne Skaret henviser også til dette begrepet i sin doktoravhandling om litterære kulturmøter. "Liminalitet viser til et område imellom ('inbetween')

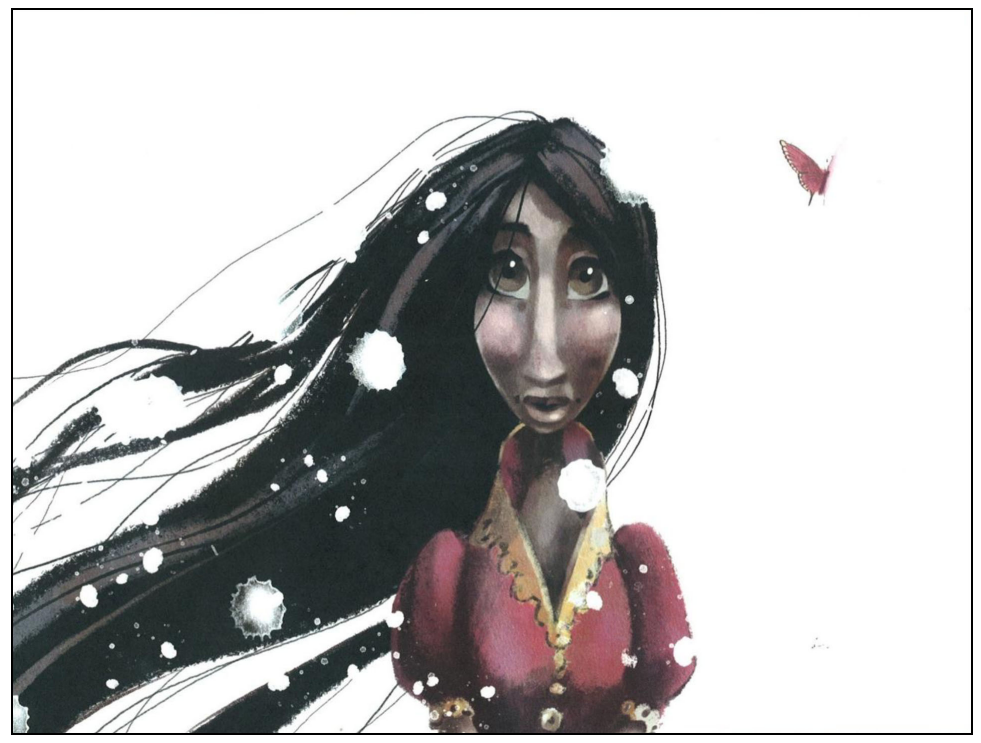

Figur 4. Skylappjenta etterlates i et stort tomrom. Oppslag 17. Gjengitt med tillatelse fra Endre Skandfer og forlaget. 
kulturer, hvor kulturell endring kan finne sted" (Skaret, 44). Begrepet er utviklet av den indisk-amerikanske litteraturteoretikeren Homi K. Bhabha, som i sine postkoloniale studier trekker fram kulturens grenser som et undervurdert område $\mathrm{i}$ en tid som fokuserer på kulturelt mangfold ("cultural diversity"). Det er nettopp det at de kulturelle forskjellene blir uttrykt, som aktualiserer spørsmål om hva som er gyldig og relevant kulturell kunnskap, og hvilken autoritet den skal tillegges: "cultural difference is the process of the enunciation of culture as 'knowledgeable', authoritative, adequate to the construction of systems of cultural identification" (50). Skylappjentas situasjon kan stå som eksempel på forandringer som følger av globalisering fordi kulturtradisjoner som før har vært knyttet til geografiske steder endres ved at de forflyttes og kommer i kontakt med andre tradisjoner. Men ifølge blant annet kultursosiologen John Tomlinson er ikke erfaringene på individnivå utelukkende negative:

However this is not typically experienced as simply cultural loss or estrangement but as a complex and ambigous blend: of familiarity and difference, expansion of cultural horizons and increased perceptions of vulnerability, access to the "world out there" accompanied by penetration of our private worlds, new opportunities and new risks (128).

\section{Fra refleksiv identitet til kulturell identitet}

I Modernitet och självidentitet. Självet och samhället $i$ den senmoderna epoken ser sosiologen Anthony Giddens nærmere på hvordan individet i dag må konstruere sin identitet på bakgrunn av både personlig og sosial forandring. I tradisjonelle kulturer var identiteten på en helt annen måte fastlagt fra samfunnets side. Både forpliktelser og rettigheter var klarlagt på forhånd og i liten grad gjenstand for forhandlinger og forandringer. Gjennom blant annet bestemte overgangsritualer gikk en person fra å være ungdom til å bli voksen. I senmoderniteten må derimot individet selv utforske og skape sin identitet som en del av en refleksiv prosess: "Ju mer traditionen mister sitt grepp, och ju mer vardagslivet rekonstitueras mot bakgrund av det dialektiska samspelet mellan det lokala och det globala, desto mer tvingas individerna att komma fram til en livsstil bland många olika alternativ" (13).

Kultursosiologen Stuart Hall understreker, på linje med Giddens, at identitet er en konstruksjon, en prosess som aldri tar slutt. Men hans drøfting av identitetsbegrepet legger mer vekt på 
kulturens rolle i slike prosesser, og får dermed fram hvordan identitet kan være motsetningsfylt og sammensatt: "[...] identities are never unified and, in late modern times, increasingly fragmented and fractured; never singular but multiply constructed across different, often intersecting and antagonistic, discourses, practices and positions" (4).

Her ser vi en helt annen forståelse av identitet enn den som vi så Åsfrid Svensen framhevet som det ideologiske grunnlaget for hjemme - borte - hjemme strukturen i barnelitteraturen. Hall framhever identifikasjon som en prosess der man artikulerer, sammenføyer og tydeliggjør forskjeller som aldri helt lar seg viske ut. Det dreier seg om å skape tradisjon; om hva man kan bli, mer enn om hvem man er eller hvor man kommer fra. Eller, som Hall selv uttrykker det med et ordspill: "not the so-called return to roots, but a coming-to-terms-with our 'routes'"' (4).

Et hovedpoeng hos Hall er at identiteten konstrueres i møte med samfunnets diskurser, og at identifikasjonsprosessen bearbeides diskursivt. Identitet dreier seg ikke om en uforanderlig kjerne, men snarere om de begrepene og fortellingene vi bruker til å tenke om oss selv og vår posisjon med. Og identiteten formes like mye ved å få klart fram hvem og hva man ikke er, som ved identifikasjon med visse personer, grupper eller verdier.

Som vi har sett ovenfor, legger også Homi K. Bhabha vekt på at det er i selve utsigelsen at kulturelle forskjeller inviterer til identifikasjon. Han trekker fram tre betingelser for å forstå slike identifikasjonsprosesser: For det første er de relasjonelle, det er ved å se seg selv i forhold til andre ("the place of the Other") at subjektet settes $i$ bevegelse. For det andre foregår slike identifikasjonsprosesser i det vi ovenfor har kalt liminaliteten, der kulturelle forskjeller blir synlige. Sist, men ikke minst understreker Bhabha at det aldri er snakk om å komme fram til en bekreftelse på en på forhånd gitt identitet. Identitetsarbeidet er en prosess der subjektet produserer nye identitetsbilder og dermed blir forandret (63-64).

Skylappjenta mellom tradisjon og selvrealisering

For Skylappjenta kjennetegnes denne hjemløs-fasen av å stå i en posisjon mellom tradisjon og selvrealisering. Hun må velge en livsstil blant "många olika alternativ". Hun velger bort den tradisjonelle kvinnerollen som hennes mor og bestemor representerer. I bildene framstilles de to eldre kvinnene hele tiden med hver sin skylapp-lue. Lua fungerer som et symbol på konvensjonelle kjønnsroller i 
en tradisjonell patriarkalsk kultur hvor kvinner sosialiseres inn i underdanige roller. I begynnelsen lever Skylappjenta opp til dette kvinneidealet: "Jenta hadde ikke for vane å klage, men gjorde som hun ble fortalt og kranglet aldri" (oppslag 1). Når da Skylappjenta til slutt river av seg lua, trosser hun restriksjoner som er forbundet med en slik kvinnerolle. Hun tydeliggjør både for seg selv og omverdenen at hun ikke lenger vil la lua forme hennes identitet som ung kvinne. Giddens påpeker at klesdrakt kan fungere som et symbolsk uttrykk: "Kläder är i alla kulturer något mycket mer än bara ett sätt att skydda kroppen: de är helt uppenbart ett medel för individen att symboliskt visa upp sig, ett sätt att ge självidentitetens berättelser en yttre form" (78).

Slik blir påkledningen for Skylappjenta en utsigelse (Bhabha: "enunciation") av kulturelle forskjeller, og ved sin handling tar hun aktivt stilling til dem.

"Så annerledes" er Skylappjentas første reaksjon når hun erfarer omverdenen uten at skylappene sperrer for utsynet (oppslag 16). Uten lua som identitetsmarkør må hun selv velge veien videre. Anthony Giddens påpeker at noe av det som særpreger senmoderniteten, er det mangfoldet av valg individet må ta stilling til uten å kunne støtte seg til den fastlagte rammen som tradisjonen før tilbød. Han bruker begrepet "ödesdigra ögonblick" om slike situasjoner hvor det enkelte individ må ta valg som kan få store konsekvenser for individets videre utvikling. Skylappjenta står på mange måter ved et slikt eksistensielt veiskille:

Ödesdigra ögonblick utgör ett hot mot den skyddshinna som försvarar individens ontologiska trygghet eftersom "allt-är-som-vanligt"-attityden, som är så viktig för denna skyddshinna, oundvikligen rämnar. Det är ögonblick då individen måste kasta sig ut i något nytt med insikt om att det beslut som fattas, eller den handlingsinriktning som väljs, har en irreversibel karaktär eller att det åtminstone blir svårt att efter detta återvända till gamla banor (139).

Selv i en sårbar posisjon vet Skylappjenta at hun må videre uten å dvele for lenge ved fortiden. Også Normann er et tilbakelagt kapittel: "Skylappjenta snudde seg og så tilbake på skogen. Hun snufset litt og tenkte på moren, bestemoren, onkel Chacha og Normann. Så tørket hun tårene og rettet blikket framover. Hun tok ett skritt, og ett til og gikk mot den store byen" (oppslag 16). 
Slik forteller boka mer om hva Skylappjenta forlater, enn om hva framtiden vil bringe.

\section{Et senmoderne eventyr til å tenke med}

I Skylappjenta ser vi hvordan eventyrtradisjonen tas i bruk for å stille samtidens spørsmål om identitet, og spesielt kvinneidentitet i et flerkulturelt samfunn. De unge leserne - barn eller ungdom har noen før-forventninger når de gjenkjenner eventyret om Rødhette. I Skylappjenta får samspillet mellom dette gamle eventyret og aktuelle spørsmål i dagens samfunn den unge leseren til å se paralleller og trekke sine egne konklusjoner: de kan lure på hvem som er den egentlige ulven i Skylappjenta, eller på hvilken måte slutten kan oppfattes som lykkelig. Ved å bruke eventyrstrukturen i samtidslitteratur, har også Iram Haq og Endre Skandfer muligheten både til å forenkle og overdrive, for eksempel ved å framheve kulturelle forskjeller i en dikotomi mellom den arkaiske ikkevestlige kulturen basert på eldgamle æresbegreper og det senmoderne norske samfunnet som er preget av overfladiske verdier. Slik gjør teksten forskjellene tydelige, og produserer det Stuart Hall kaller "frontier-effects" (3), og Bhabha "the disturbing distance in-between" (64).

Slik tydeliggjøres også kjønnsrollene ved å vise et ensidig bilde av hvordan kvinnerollen søkes overført fra bestemor og mor til datter. I mange eventyr fungerer den eldre kvinnen som en ond makt som protagonisten må overvinne eller unnslippe, for eksempel stemora i Snehvit og heksa i Rapunsel. I Skylappjenta er det særlig bestemora som blir skildret med negative karaktertrekk. Hun står også i ledtog med onkel Chacha. Både verbaltekst og bilde understreker den gamle kvinnens innflytelse. Hennes besettelse når det gjelder mat karikeres: "Mellom matbitene messet bestemoren innstendig på en bønn for å redde familiens ære" (oppslag 11). Denne latterliggiøringen antyder at hun kan være like grådig som ulven. Men da er det nærliggende å stille seg spørsmålet om hun er like farlig også.

I Skylappjenta brytes den tradisjonelle eventyrstrukturen ved den åpne slutten, der Skylappjenta ikke er brakt "hjem" igjen til en ny harmonitilstand. Og i motsetning til de andre eventyrheltinnene er hun, som vi har påpekt tidligere, helt alene, uten hjelpere. I krysspresset mellom den arkaiske ikke-vestlige kulturen og senmodernitetens valgmuligheter har hun høstet erfaringer som 
må bearbeides før hun kan bygge opp sin identitet som ung, uavhengig kvinne. Byen representerer muligheten for en ny tilværelse hvor hun selv må reflektere over situasjonen og ta egne avgjørelser. Det siste dobbeltoppslaget viser lua som ligger tilbake i snøen og fotsporene som peker mot byen langt der borte. Som vanlig i eventyr er slutten positiv, men den viser senmoderne trekk ved at den også er åpen: "Bare Skylappjenta vet om hun fant det hun lengtet etter. Og har hun ikke funnet det ennå, så er hun nok på god vei."

Om dette er en lykkelig slutt, er avhengig av øynene som ser. Fortellingen fører Skylappjenta fram til et punkt hvor det står klart for henne hvem hun ikke vil være. Hun har erklært at hun klarer seg fint uten familien og deres trange normer for livet hennes (oppslag 13). Normann er ute av bildet, og det er ingenting som tyder på at løsningen for Skylappjenta er å følge etter sin prins og vinne ham tilbake, slik tidligere kvinnelige eventyrerhelter har gjort. Denne tilstanden av hjemløshet innebærer en mulighet til å gjøre egne valg om hva hun setter sin ære i. Slik kan hun konstruere en ny identitet som riktignok kan være spenningsfylt og motsetningsfylt, slik hennes egen bakgrunn også er det.

\section{Konklusjon}

Skylappjenta representerer et viktig stykke senmoderne identitetsarbeid. Den gir ikke ett enkelt svar på spørsmålet om identitet; de enkle svarene som tilbys er utilfredsstillende enten man ser dem med norsk eller pakistansk blikk. Slik framheves identitet i et globalisert samfunn ikke som en stabil tilstand, men som en prosess kjennetegnet av hybriditet, der identiteten stadig må erobres, ved å gi den relevante uttrykk og forestillinger til utprøving. Tilstanden av hjemløshet som Skylappjenta befinner seg i ved slutten av boka, er nettopp et "sted" der slike identitetsprosesser settes i spill på en særlig måte. Ved å fokalisere jenta som befinner seg i en minoritetskultur med sterke uttrykk og tradisjoner, kommer de kulturelle forskjellene i forgrunnen, og det skapes et rom for dynamisk identitetsarbeid. Det dreier seg om en identitet som ikke kan slå seg til ro med å lande i en ny "hjemme"-harmoni, en identitet som er framtidsrettet mer enn tilbakeskuende. Denne identiteten blir til diskursivt (Hall) gjennom tekster og uttrykk som viser fram de kulturelle forskjellene. Skylappjenta skaper et felles utgangspunkt ved å bruke velkjente eventyrgrep, men bokas viktigste bidrag er at den viser fram spenninger og motsetninger 
som skaper et fortolkningsrom der leseren kan utforske ulike mulige identitetsbilder.

Bibliografisk informasjon: Hanne Kiil er Cand. Philol., formidlingsrådgiver og litteraturpedagog ved Norsk barnebokinstitutt. Elise Seip Tønnessen er Dr. Philos., professor ved Institutt for nordisk og mediefag ved Universitetet i Agder og forskningsleder ved Norsk barnebokinstitutt.

\section{Bibliografi}

Asbjørnsen, P.C. og Jørgen Moe. Norske folkeeventyr. 1842. Oslo: Aschehoug, 2012.

Beckett, Sandra L. Recycling Red Riding Hood. New York and London: Routledge, 2002.

Beckett, Sandra L. Red Riding Hood for All Ages - A Fairy-Tale Icon in CrossCultural Contexts. Detroit: Wayne State University Press, 2008.

Bettelheim, Bruno. Sagans förtrollade värld. Folksagornas innebörd och betydelse. 1975. Oversatt av Disa Törngren. Uppsala: 1980.

Bhabha, Homi K. The Location of Culture. London and New York: Routledge, 1994.

Giddens, Anthony. Modernitet och självidentitet. Självet och samhället $i$ den senmoderna epoken. Gøteborg: Daidalos, 2009.

Grimm, Brødrene. Samlede eventyr. Oversatt av Nanna Qvam. Oslo: Damm, 2001.

Hall, Stuart. "Introduction: "Who needs 'identity'?" I Questions of Cultural Identity. Red. Stuart Hall \& Paul du Gay London. Thousand Oaks, New Dehli: Sage, 1996, 1-17.

Haq, Iram og Endre Skandfer. Skylappjenta. Oslo: Cappelen Damm, 2009.

Kiil, Hanne. "Fordi jeg fortjener det? - trender og tendenser i norske ungdomsbøker 2009." Oslo: Norsk barnebokinstitutt. http:// barnebokinstituttet.no/formidling/trender_og_tendenser/fordi_jeg_fortjener_ det Publisert 28.01.2010.

Kramer, Hilde. Østenfor sol og vestenfor måne. Oslo: Cappelen, 1991.

Little Miss Eye Flap. Oslo: Storm Films, 2009.

May, Rollo. Myter og identitet: behovet for myter $i$ vår tid. Oversatt og redigert av Geir Uthaug. Oslo: Aventura, 1992.

Nikolajeva, Maria. Power, Voice and Subjectivity in Literature for Young Readers. New York: Routledge, 2010.

Naveen, Neha. "Fjellene møtes ikke, men mennesker kan." En analyse av møtet mellom globalisering og norsk barnelitteratur. Masteroppgave, Høgskolen i Telemark, 2011. 
Ommundsen, Åse Marie. "Eventyr på nye veier. Multimodale nyskrivninger av eventyr i skandinavisk samtidslitteratur". Till en evakuerad igelkott. Festskrift til Maria Nikolajeva. Red. Maria Lassén-Seger og Mia Österlund. Göteborg: Makadam Förlag, 2012, 231-242.

Perrault, Charles. Histoires ou Contes du temps passé det moralités. 1697.

Propp, Vladimir. Morphology of the Folk Tale. 1928. Oversatt av Laurence Scott. Austin: Texas University Press, 1968.

Reimer, Mavis og Bradford, Clare. "Home, Homelessness and Liminal Spaces: The Uses of Postcolonial Theory for Reading (National) Children's Literatures". Children's Literature Global and Local: Social and Aesthetic Perspectives. Red. Emer O. Sullivan, Kimberley Reynolds og Rolf Romøren. Oslo: Novus, 2005, 200-217.

Said, Edward. Culture and Imperialism. New York: Knopf, 1993.

Said, Edward. Orientalismen. Vestlige oppfatninger av Orienten. 1978. Oslo: De norske bokklubbene, 2001.

Skaret, Anne. Litterære kulturmøter. En studie av bildebøker og barns resepsjon. Ph.d. avhandling, Universitetet i Oslo, 2012.

Svensen, Åsfrid. "Fra store fortellinger til små historier - Nye narrative strukturer i moderne barne- og ungdomslitteratur". A bygge en verden av ord. Bergen: Fagbokforlaget, 2001.

Skjønsberg, Kari. "Rødhette - hvem er du?" Red. Harald Bache-Wiig. Norskrift nr. 88. Oslo: Universitetet i Oslo, 1996, 9-28.

Stewart, Frank Henderson. Honor. Chicago: The University of Chicago Press, 1994.

Tomlinson, John. Globalization and Culture. Cambridge: Polity Press, 1999.

Wall, Barbara. The Narrator's Voice: the Dilemma of Children's Fiction. Basingstoke: Macmillan, 1991.

Wikan, Unni. For œrens skyld. Oslo: Universitetsforlaget, 2003/2005.

Wikan, Unni. Om ære. Oslo: Pax forlag, 2008.

Witoszek, Nina. Norske naturmytologier. Oslo: Pax forlag, 1998.

Witoszek, Nina. The Origins of the "Regime of Goodness". Remapping the Cultural History of Norway. Oslo: Universitetsforlaget, 2011. 